\title{
Complementary and alternative medicine usage in patients with Familial Mediterranean Fever
}

\author{
(1) Seda Çolak', (1) Emre Tekgöz', (1) Fatma İlknur Çınar², (1) Sedat Yılmaz', (1) Muhammet Çınar \\ 1 University of Health Sciences Turkey, Gülhane Faculty of Medicine, Department of Internal Medicine, Division of Rheumatology, \\ Ankara, Turkey \\ 2University of Health Sciences Turkey, Gülhane Faculty of Nursing, Department of Internal Medicine Nursing, Ankara, Turkey
}

\section{Date submitted: \\ 19.02.2020}

Date accepted:

20.04.2020

Online publication date:

15.12.2020

\section{Corresponding Author:}

Seda Çolak MD, University of Health Sciences Turkey, Gülhane Faculty of Medicine, Department of Internal Medicine, Division of Rheumatology, Ankara, Turkey

sedayurumez@hotmail.com

ORCID:

orcid.org/0000-0002-5703-6739

Keywords: Colchicine, complementary and alternative medicine, Familial Mediterranean Fever

\begin{abstract}
Aims: Colchicine is mainstay in the treatment of Familial Mediterranean Fever (FMF). In chronic diseases, complementary and alternative medicine (CAM) methods can be chosen as a nonmainstream treatment. We aimed to identify the prevalence and the associated factors for the use of CAM in patients with FMF.
\end{abstract}

Methods: Data of 165 patients were obtained from patients' medical records and face-to-face interviews. Using any type of CAM methods and patients' having harm and/or benefit were analyzed. The Morisky Green Levine Scale was used to assess the treatment adherence and the Beliefs About Medicines Questionnaire was used to assess the patient's beliefs about medicines.

Results: Fifty-six (33.9\%) patients were using CAM. The frequency of patients with the concomitant disease was higher in the CAM user group (35.7\%) compared to the CAM non-user group $(18.3 \%)\left(x^{2}=6.075, p=0.014\right)$. The frequency of patients who had a positive family history for FMF was higher in the CAM user group (78.6\%) compared to the CAM non-user group $(58.7 \%)\left(x^{2}=6.450, p=0.011\right)$. The number of patients who reported benefit from CAM was 42 (75.0\%). The median score of concern about colchicine was 3.2 among CAM users, whereas 2.8 among CAM non-users $(p=0.035)$. No relationship was found between the compliance with colchicine treatment and the usage of CAM $(p=0.313)$.

Conclusions: Concomitant diseases in patients, FMF in relatives, and concerns about colchicine may rise the tendency to CAM using. Patients should be well-informed about that CAM methods cannot be an alternative to colchicine.

\section{Introduction}

Familial Mediterranean Fever (FMF) is the most common hereditary periodic fever syndrome. It has a high prevalence among Turks, Armenians, Arabs, and Jaws. The prevalence of FMF in Turkey is approximately $0.093 \%$ (1). The disease is characterized by recurrent attacks of serositis (peritonitis, pleuritis, pericarditis or arthritis) and fever (2). Frequent FMF attacks lead to the deposition of amyloid in visceral organs. The most important complication of amyloidosis is renal failure. Colchicine reduces the frequency and severity of febrile attacks and the risk of amyloidosis $(3,4)$. Approximately $5-10 \%$ of patients may be resistant to colchicine. Biological drugs can be used off-label in the treatment of these patients (5-7).
According to the National Institutes of Health, complementary and alternative medicine (CAM) modalities can be defined as products and practices which are distinct from conventional therapies of the diseases. There are several types of CAM; natural products, manipulative practices, mind-body interventions, and energy therapies. Types of CAM therapies and frequency of use can vary among countries and cultures. Complementary therapy may be used together with conventional therapy; on the other hand, alternative therapy is generally used in place of conventional therapy. Adverse effects, especially those with herbal products, should be considered carefully (8-10).

The frequency of CAM usage among FMF patients is not established yet. The current study aimed to identify the 
frequency of CAM using and the factors related to the usage of CAM in patients with FMF.

\section{Methods}

\section{Study Design, Sample, and Setting}

This cross-sectional descriptive study was conducted in a tertiary rheumatology outpatient clinic between February and August 2019. The study design was approved by the Local Ethical Committee of Gülhane Training and Research Hospital (approval number is 19/46). Written informed consent form was obtained from each participant before any study-related procedure was performed in accordance with the principles of the Helsinki Declaration.

In the current study, 165 patients with FMF were included. The inclusion criteria were; (a) having been diagnosed with FMF according to the Tel-Hashomer criteria (11), (b) being aged 18 years and older, (c) being able to read, write, and speak in Turkish, and (d) being a volunteer to participate in this study. The exclusion criteria were; i) being pregnant, ii) being diagnosed with major psychiatric diseases, iii) having concurrent terminal illness or being unstable clinically, and iv) having cognitive impairment.

\section{Data Collection, Procedure}

Demographic and clinical data were obtained from patients' files and face-to-face interviews. Interviews were conducted in outpatient rooms. The interviews took a mean of 20-25 minutes. Firstly, interviewers asked if the patients used CAM. The outcomes of CAM usage were questioned if the answer was positive. The disease severity of patients was evaluated using the International Severity Scoring System for FMF (ISSF) (12). The Morisky Green Levine Scale (MGLS) was used to analyze the adherence of the patients with their treatment (13). This scale consists of 4-item. Each item asks patients whether they exhibit a specific type of non-adherent behavior. For each item, answers 'yes' and 'no' are scored as 1 and 0 , respectively. The scores of MGLS range from 0 to 4 . In the current study, the patients who scored 0 were accepted as "adherent" whereas those who scored $\geq 1$ were accepted as "non-adherent". The Beliefs About Medicines Questionnaire (BMQ-T), which was validated for Turkish population by Cinar et al. $(14,15)$, was used to assess patient's perceptions and expectations about medications. The BMQ-T has two sections with a total of 18 items; BMQ-T specific and BMQ-T general. BMQ-T specific, which consists of two subgroups (Specific-Necessity and Specific-Concern), is used to assess the patient's beliefs and concerns about one's personal disease and medicine. BMQ-T General also consists of two subgroups, General-Harm and General-Overuse, which are used to assess the patient's general beliefs and perceptions about medicines. Participants indicate the degree of agreement for each statement on a 5-point Likert scale ranging from strongly disagree [1] to strongly agree [5]. An average score for each sub-scale is calculated by dividing the total score for these scales by the number of items in the scale, and a mean score range between 1 and 5 is obtained for each sub-scale. The higher scores of each section indicate a stronger belief in the concept of that section.

\section{Statistical Analysis}

Statistical Package for the Social Sciences version 18 was used for statistical analysis. Descriptive statistics were presented as mean \pm standard deviation [median (minimummaximum)] values for measured variables, and frequency and percentage (\%) for categorical data. Categorization was done on the basis of CM use. The Spearman correlation coefficient was used to evaluate the association between variables. The Mann-Whitney $U$ test, Pearson chi-square test, Fisher's exact test, and Student's t-test were used to analyze data. Calculated $p$ value less than 0.05 was accepted as statistically significant.

\section{Results}

A total of 165 patients [58 (35.2\%) female and 107 (64.8\%) male] were included in the study. The mean age of the participants was $34.1 \pm 12.7$ years. The median illness duration was 14.0 years. One hundred and forty-five $(87.9 \%)$ had peritonitis, $141(85.5 \%)$ had fever, $66(40 \%)$ had febrile myalgia, $61(37 \%)$ had arthritis, $59(35.8 \%)$ had pleuritis, 37 (22.4\%) had erysipelas like erythema, $2(1.2 \%)$ had pericarditis, $2(1.2 \%)$ had orchitis during attacks. Twenty-two patients $(13.3 \%)$ had proteinuria (150 mg/24 hours) and amyloidosis was detected in $7(4.2 \%)$ patients. One hundred and fifty-one $(91.5 \%)$ patients had MEFV gene mutations and the most frequent mutation was M694V (70.3\%). Twenty-three percent of the patients had adverse events related to colchicine. The most common adverse events due to colchicine use were gastrointestinal adverse events, and usually diarrhea. Nineteen (11.5\%) patients were resistant to colchicine treatment. According to their ISSF scores, $70(42.4 \%)$ patients had mild disease, $82(49.7 \%)$ had moderate disease, and $13(7.9 \%)$ had severe disease. Forty-eight patients had comorbidities and the most common comorbid disease was hypertension in $14(8.5 \%)$ patients. Other common comorbid diseases were $6(3.6 \%)$ asthma, $5(3.0 \%)$ ankylosing spondylitis, 4 (2.4\%) Henoch Schönlein purpura, and $4(2.4 \%)$ diabetes mellitus. No statistically significant difference was found between the CAM user group and the CAM nonuser group in terms of age, gender, relationship, socioeconomic and employment status, the distance of the patient to the treatment center, dosage of colchicine, adverse events seen with colchicine treatment, characteristics of febrile attacks, the frequency of febrile attacks, severity of illness, presence of amyloidosis, and chronic renal failure $(p>0.05)$. The number of patients with the concomitant disease was $20(35.7 \%)$ in the CAM user group and $20(18.3 \%)$ in the CAM non-user group 
$\left(x^{2}=6.075, p=0.014\right)$. Patients with a positive family history for FMF were higher in the CAM user group compared to the CAM non-user group. The frequency of relatives with FMF was $78.6 \%$ in the CAM user group, whereas $58.7 \%$ in the CAM non-user group $\left(x^{2}=6.450, p=0.011\right)$. The sociodemographic and clinical characteristics of patients and comparisons between CAM user and CAM non-user patients were shown in Table 1.
The number of patients using at least one CAM was 56 (33.9\%). Benefit from CAM was reported by 42 (75.0\%) patients. The mean duration of using CAM therapies was $7.9 \pm 6.4$ years. The most frequently chosen types were massage therapy $(12.1 \%)$, guided imagery $(9.7 \%)$, relaxation techniques $(9.1 \%)$, cupping $(9.1 \%)$, and natural products $(9.1 \%)$ (Table 2$)$.

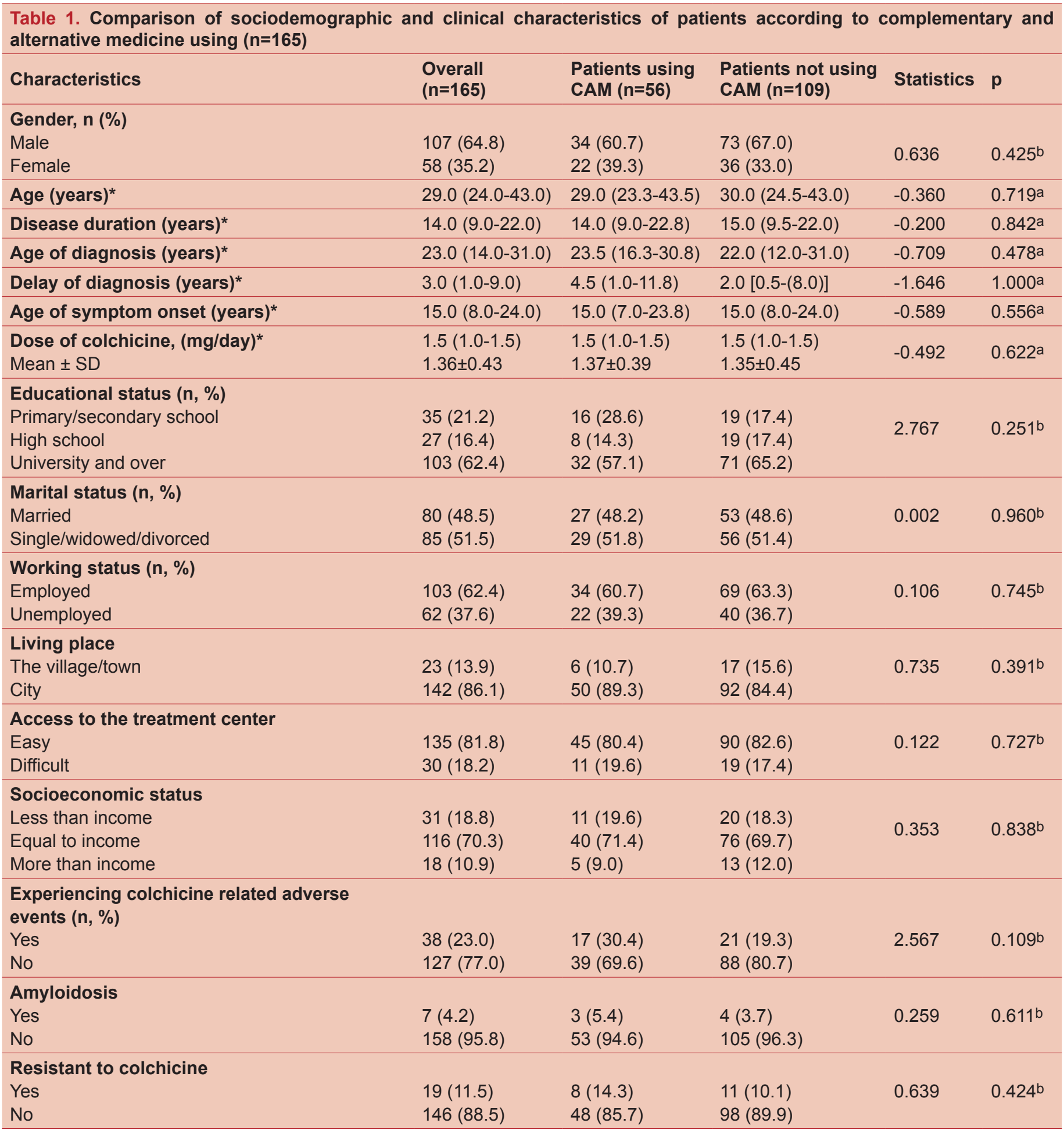




\begin{tabular}{|c|c|c|c|c|c|}
\hline Characteristics & $\begin{array}{l}\text { Overall } \\
(n=165)\end{array}$ & $\begin{array}{l}\text { Patients using } \\
\text { CAM }(n=56)\end{array}$ & $\begin{array}{l}\text { Patients not using } \\
\text { CAM }(n=109)\end{array}$ & Statistics & p \\
\hline \multicolumn{6}{|c|}{ History of FMF in relatives } \\
\hline Yes & $108(65.5)$ & $44(78.6)$ & $64(58.7)$ & \multirow[t]{2}{*}{6.450} & \multirow[t]{2}{*}{$0.011^{b}$} \\
\hline No & $57(34.5)$ & $12(21.4)$ & $45(41.3)$ & & \\
\hline \multicolumn{6}{|c|}{ Presence of MEFV mutations } \\
\hline Yes & $151(91.5)$ & $54(96.4)$ & $97(89.0)$ & \multirow[t]{2}{*}{2.636} & \multirow[t]{2}{*}{$0.104^{b}$} \\
\hline No & $14(8.5)$ & $2(3.6)$ & $12(11.0)$ & & \\
\hline \multicolumn{6}{|l|}{ Comorbidities } \\
\hline Yes & $40.0(24.2)$ & $20(35.7)$ & $20(18.3)$ & \multirow[t]{2}{*}{6.075} & \multirow[t]{2}{*}{$0.014^{b}$} \\
\hline No & $125(75.8)$ & $36(64.3)$ & $89(81.7)$ & & \\
\hline \multicolumn{6}{|c|}{ Disease severity according to ISSF } \\
\hline Mild & $70(42.4)$ & $17(30.4)$ & $53(48.6)$ & \multirow{3}{*}{5.099} & \multirow{3}{*}{$0.078^{b}$} \\
\hline Moderate & $82(49.7)$ & $34(60.7)$ & $48(44.0)$ & & \\
\hline Severe & $13(7.9)$ & $5(8.9)$ & $8(7.4)$ & & \\
\hline
\end{tabular}

\begin{tabular}{ll}
\hline \multicolumn{2}{|l}{ Table 2. Prevalence of complementary and alternative } \\
medicine modality types used among patients \\
\hline Type of CAM therapy & Total $\mathbf{n}(\%)^{*}$ \\
\hline Massage therapy & $20(12.1)$ \\
\hline Guided imagery & $16(9.7)$ \\
\hline Relaxation techniques & $15(9.1)$ \\
\hline Cupping & $15(9.1)$ \\
\hline Natural products & $15(9.1)$ \\
\hline Ginger and curcuma & $2(1.2)$ \\
Camomile and balm & $2(1.2)$ \\
Sage tea and various types of tea & $2(1.2)$ \\
Black seed oil & $2(1.2)$ \\
Cherry stem & $1(0.6)$ \\
Sycamore leaf & $1(0.6)$ \\
Avocado leaf & $1(0.6)$ \\
Milk thistle & $1(0.6)$ \\
Ringel blume & $1(0.6)$ \\
\hline Mint and lemon & $1(0.6)$ \\
Centaury & $1(0.6)$ \\
\hline Breathe therapy & $10(6.1)$ \\
\hline Art therapy & $6(3.6)$ \\
\hline Hydrotherapy & $2(1.2)$ \\
\hline Yoga & $2(1.2)$ \\
\hline Meditation & $2(1.2)$ \\
\hline Electric stimulation therapy & $2(1.2)$ \\
\hline *The number of patients stating that they have used CAM modalities. Patients \\
marked more than one method. & \\
CAM: Complementary and alternative medicine & \\
\hline & \\
\hline
\end{tabular}

According to the BMQ-T specific, the patients who were CAM users, had a higher rate of concern about colchicine. The median score of BMQ-T specific concerns was 3.2 among patients who were using CAM and 2.8 among patients who were not using CAM ( $p=0.035$ ) (Table 3 ). No significant correlation was found between adherence to colchicine treatment and using CAM regarding MGLS scores ( $p=0.313)$.

\section{Discussion}

According to our knowledge, this is the first study evaluating the use of CAM therapies among patients with FMF. Approximately one-third of patients were using at least one type of CAM therapies. The World Health Organization defines CAM therapies as a broad range of health services that are not part of the country's traditional practices and behaviors and are not integrated into the dominant health system $(16,17)$.

There are several reasons that can motivate patients to use CAM methods, such as failure or inadequate response to conventional treatments, reliability, and assumed positive experiences.

The gold standard for treating FMF is colchicine due to its known effect on decreasing the severity and frequency of FMF attacks and the risk of development of amyloidosis (3). Because of the early-onset and chronic course of the disease, patients may seek an alternative treatment method.

In the current study, 56 (33.9\%) patients were using at least one type of CAM therapies. There are several studies in the literature observing the prevalence of using CAM therapies among patients with rheumatic diseases. The prevalence of CAM users differs from $22 \%$ to $95 \%$ in the literature (18-21). Among patients with fibromyalgia, the prevalence may increase by up to $98 \%$ (22). There are few studies from Turkey, which evaluate CAM usage among patients with rheumatic disease. The frequency of CAM using is $76.0 \%$ among patients with arthritis, $46.9 \%$ among patients with rheumatoid arthritis (RA), 


\begin{tabular}{|c|c|c|c|c|c|}
\hline Variable & $\begin{array}{l}\text { Overall } \\
(n=165)\end{array}$ & $\begin{array}{l}\text { Patients using } \\
\text { CAM }(n=56)\end{array}$ & $\begin{array}{l}\text { Patients not } \\
\text { using CAM } \\
(n=109)\end{array}$ & Statistics & $\mathbf{p}$ \\
\hline BMQ-T-Specific Necessityc & $4.0(3.4-4.6)$ & $4.0(3.6-4.6)$ & $4.0(3.3-4.6)$ & $-0.410^{a}$ & 0.682 \\
\hline BMQ-T-Specific Concernsc & $2.8(2.4-3.6)$ & $3.2(2.6-3.8)$ & $2.8(2.4-3.6)$ & $-2.110^{a}$ & 0.035 \\
\hline BMQ-T-General Harmc & $2.3(2.0-3.0)$ & $2.4(2.0-3.0)$ & $2.3(2.0-3.0)$ & $-0.858 a$ & 0.391 \\
\hline Morisky Green Levine Scale Adherenced & $37(22.4)$ & $10(27.0)$ & $27(73.0)$ & \multirow{2}{*}{$0.016^{b}$} & \multirow{2}{*}{0.313} \\
\hline Non-adherence ${ }^{d}$ & $128(77.6)$ & $46(35.9)$ & $82(64.1)$ & & \\
\hline \multicolumn{6}{|c|}{$\begin{array}{l}\text { aMann-Whitney } U \text { test, bPearson chi-square test. } \\
\text { cVariables were given as median }\left(25^{\text {th }}-75^{\text {th }} \text { percentile). }\right. \\
\text { dVariables were given as } n(\%) \text {. } \\
\text { CAM: Complementary and alternative medicine, BMQ-T: Beliefs about Medicines Questionnaire Turkish translation }\end{array}$} \\
\hline
\end{tabular}

and $36.6 \%$ in ankylosing spondylitis among Turkish patients (23-25).

Massage therapy was the most popular CAM modality in our study. Although natural products and herbs are a part of traditional culture in Turkey, the patients rarely mentioned the use of herbal remedies. This may be related to the concern of possible interaction between herbal remedies and colchicine. On the other hand, certain CAM therapies such as Ayurveda, Tai Chi, and Reiki, which are well known and widely used in Far East countries, are not widely known and used in Turkey.

According to the study results, the rate of CAM usage is higher among FMF patients with a positive family history. This may be related to advices or learned behaviors from close relatives. Also, the current study indicated that having a concomitant disease was associated with the increased use of CAM. CAM therapies were widely used for preventing chronic pain. Therefore, providing pain control in patients with multiple diseases may be related to increased use of CAM therapies. On the other hand, patients may wish to decrease the number of drugs they use for comorbid diseases. Chronic concomitant diseases of the patients may lead to a decrease in the compliance of the patients with drugs and increase the usage of CAM modalities.

In a previous study conducted among patients with rheumatic diseases, a significant association was found between using CAM therapies and being female, young and having poor health status (18). Another study showed that higher education and employment were associated with higher rates of CAM use (26). However, our study found no significant association between the use of CAM and age, gender, educational or social status.

Lahiri et al. (27) showed that CAM therapies might lead to a delay in the treatment of early RA patients. Physicians should be careful with inadequate or delayed colchicine treatment for FMF patients who were using CAM.
The current study had some limitations. First, the history of CAM use was not evaluated. Secondly, because of the crosssectional design of the study, longitudinal data could not be shown. Some of the patients may be reluctant to declare the use of CAM. Besides, the guiltiness regarding utilizing CAM therapies may lead patients to hide this from physicians. These situations may be related to the lower incidence of CAM users.

\section{Conclusion}

In conclusion, tendency of CAM using may raise as a result of the concerns about colchicine. Patients should be informed about the safety of the colchicine treatment. Also, the sufficient information should be given to the patients about that types of CAM cannot be an alternative to colchicine. Studies with larger samples should be designed to identify the use of CAM therapies and to confirm the effect of CAM therapies on the disease course in patients with FMF.

\section{Ethics}

Ethics Committee Approval: The study was approved by the Local Ethical Committee of Gülhane Training and Research Hospital (19/46).

Informed Consent: Written informed consent form was obtained from each participant.

Peer-review: Externally peer-reviewed.

\section{Authorship Contributions}

Surgical and Medical Practices: S.Ç., E.T., S.Y., M.Ç., Concept: S.Ç., E.T., F.İ.Ç., S.Y., M.Ç., Design: S.Ç., E.T., F.İ.Ç., S.Y., M.Ç., Data Collection or Processing: S.Ç., E.T., F.I.Ç., S.Y., M.Ç., Analysis or Interpretation: S.Ç., E.T., F.I.Ç., S.Y., M.Ç., Literature Search: S.Ç., E.T., F.I.Ç., S.Y., M.Ç., Writing: S.Ç., E.T.

Conflict of Interest: No conflict of interest was declared by the authors. 
Financial Disclosure: The authors declared that this study received no financial support.

\section{References}

1. Ozen $S$, Karaaslan $Y$, Ozdemir $O$, et al. Prevalence of juvenile chronic arthritis and familial Mediterranean fever in Turkey: a field study. J Rheumatol. 1998;25:2445-2449.

2. Ozdogan $\mathrm{H}$, Ugurlu S. Familial Mediterranean Fever. Press Med 2019;4:e61-e76.

3. Goldfinger S. Colchicine for familial Mediterranean fever. N Engl J Med. 1972;287:1302.

4. Dasgeb B, Kornreich D, McGuinn K, Okon L, Brownell I, Sackett DL. Colchicine: an ancient drug with novel applications. Br J Dermatol. 2018;178:350-356.

5. Endo $\mathrm{Y}$, Koga $\mathrm{T}$, Ishida $\mathrm{M}$, et al. Musculoskeletal manifestations occur predominantly in patients with lateronset familial Mediterranean fever: Data from a multicenter, prospective national cohort study in Japan. Arthritis Res Ther. 2018;20:257.

6. Koga T, Migita K, Kawakami A. Biologic therapy in familial Mediterranean fever. Mod Rheumatol. 2016;26:637-641.

7. Colak S, Tekgoz E, Cinar M, Yilmaz S. The assessment of tocilizumab therapy on recurrent attacks of patients with familial Mediterranean fever: A retrospective study of 15 patients. Mod Rheumatol. 2020;10:1-3.

8. Debas $\mathrm{H}$, Laxminarayan $\mathrm{R}$, Straus $\mathrm{S}$. Complementary and Alternative Medicine. In: Disease Control Priorities in Developing Countries. 2nd edition New York: Oxford University Press; 2006.

9. Breuner C. Alternative and complementary therapies. Adolesc Med Clin. 2006;17:521-546.

10. Danve A, Deodhar AA. Complementary medicine for axial spondyloarthritis: Is there any scientific evidence? Curr Opin Rheumatol. 2018;30:310-318.

11. Sohar E, Gafni J, Pras M, Heller H. Familial Mediterranean fever. A survey of 470 cases and review of the literature. Am J Med. 1967;43:227-253.

12. Demirkaya E, Acikel C, Hashkes P, et al. Development and initial validation of international severity scoring system for familial Mediterranean fever (ISSF). Ann Rheum Dis. 2016;75:1051-1056.

13. Morisky D, Green L, Levine D. Concurrent and predictive validity of a self-reported measure of medication adherence. Med Care. 1986;24:67-74.

14. Horne R, Weinman J, Hankins M. The Beliefs about Medicines Questionnaire: the development and evaluation of a new method for assessing the cognitive representation of medication. Psychol Heal. 1999;14:1-24.

15. Cinar M, Cinar F, Acikel C, et al. Reliability and validity of the Turkish translation of the beliefs about medicines questionnaire (BMQ-T) in patients with Behçet's disease. Clin Exp Rheumatol. 2016;34:S46-S51.

16. World Health Organization. World Health Organization Traditional Medicine Strategy: 2002-2005. Geneva: World Health Organization; 2002.

17. Phang JK, Kwan $\mathrm{YH}$, Goh $\mathrm{H}$, et al. Complementary and alternative medicine for rheumatic diseases: A systematic review of randomized controlled trials. Complement Ther Med. 2018;37:143-157.

18. Klingberg E, Wallerstedt SM, Torstenson T, Hwi G, ForsbladD'Elia $H$. The use of complementary and alternative medicine in outpatients with inflammatory rheumatic diseases in Sweden. Scand J Rheumatol. 2009;38:472480.

19. Fautrel B, Adam V, St-Pierre Y, Joseph L, Clarke A, Penrod $\mathrm{J}$. Use of complementary and alternative therapies by patients self-reporting arthritis or rheumatism: results from a nationwide Canadian survey. J Rheumatol. 2002;29:24352441.

20. Jadhav MP, Jadhav PM, Shelke P, Sharma Y, Nadkar M. Assessment of use of complementary alternative medicine and its impact on quality of life in the patients attending rheumatology clinic, in a tertiary care centre in India. Indian J Med Sci. 2011;65:50-57.

21. Haija A, Schulz S. The Role and Effect of Complementary and Alternative Medicine in Systemic Lupus Erythematosus. Rheum Dis Clin N Am. 2011;37:47-62.

22. Nicassio P, Schuman C, Kim J, Cordova A, Weisman M. Psychosocial factors associated with complementary treatment use in fibromyalgia. J Rheumatol. 1997;24:20082013.

23. Tokem Y, Parlar Kilic S, Ozer S, Nakas D, Argon G. A multicenter analysis of the use of complementary and alternative medicine in turkish patients with rheumatoid arthritis: Holistic nursing practice review copy. Holist Nurs Pract. 2014;28:98-105.

24. Unsal A, Gozum S. Use of complementary and alternative medicine by patients with arthritis. J Clin Nurs. 2010;19:1129-1138.

25. Cinar F, Ozdemir O, Yilmaz S, et al. Complementary and Alternative Medicine Usage and Associated Factors in Ankylosing Spondylitis: Preliminary Results of a CrossSectional Study. Ann Rheum Dis. 2017;76:1297.

26. Chatfield SM, Dharmage SC, Boers A, et al. Complementary and alternative medicines in ankylosing spondylitis: A cross-sectional study. Clin Rheumatol. 2009;28:213-217.

27. Lahiri M, Santosa A, Teoh LK, et al. Use of complementary and alternative medicines is associated with delay to initiation of disease-modifying anti-rheumatic drug therapy in early inflammatory arthritis. Int J Rheum Dis. 2017;20:567-575. 